\title{
Some studies on Listeria Monocytogenes infection in buffaloes
}

\author{
Magda F. Essa, Hanan K. Mahmoud \\ Department of Buffalo Diseases, Animal Health Research Institute, Dokki, Giza, Egypt.
}

\begin{abstract}
The present study concerned with Listeria monocytogenes which were isolated from apparently healthy buffaloes, buffaloes suffered from abortion, bedding and silage, which were collected from different localities. From the total examined samples (375), (300 samples from apparently healthy buffaloes, bedding and silage, also 75 samples from buffaloes suffered from abortion, bedding and silage) the prevalence of $L$. monocytogenes was 11(14.7\%), isolates from buffaloes suffered from abortion, bedding and silage. All isolates were motile at room temperature, also exhibited positive CAMP test and exhibited narrow zone of $\beta$-hemolysis. Serological identification of isolates revealed 6(54.5\%) were serotype 4 while $5(45.5 \%)$ were untyped. There were differences in isolates susceptibilities to different anti-microbial agents. $L$. monocytogenes had $100 \%$ sensitivity to Ampicillin, chloramphenicol, erythromycin, tetracycline and ceftiofur sodium. Virulence of isolates was assayed by $\mathrm{I} / \mathrm{P}$ inoculation of $10^{9} \mathrm{CFU}$ in mice, all inoculated mice died within 1-5 days. PCR assay for $L$. monocytogenes isolates revealed positive amplification of $827 \mathrm{bp}$ fragment of act $\mathrm{A}$ gene.
\end{abstract}

Listeria monocytogenes is facultative intracellular Gram-positive coccobacilli that cause listeriosis. The feeding of silage, particulary silage of inferior quality, appears to predispose animals to the development of infection by Listeria (Gitter et al., 1986). Listeriosis is a frequent cause of abortion in cattle and sheep. In cases of milkborne infection, the organism is excreted to milk in an intracellular state within bovine neutrophils and macrophages (Bunning et al., 1988). Cattle and sheep shed Listeria monocytogenes in faeces and manure and these materials, along with spoiled silage have been used as fertilizer without benefit treatment which may be the most significant sources of transmission of Listeria infection to animals. Abortion, still birth, septicemia, meningitis, endocarditis, conjunctivitis, pharyngitis and flue-like illness are known to be manifestation of infection by Listeria monocytogenes.

The aim of the present investigation was directed to the following. Isolation of Listeria monocytogenes from apparently healthy buffaloes, aborted buffaloes, bedding and silage. Determination of the pathogenicity of the isolates in mice, motility test, CAMP test and hemolytic activity on blood agar. Serological identification of $L$. monocytogenes isolates. Determination of antibiogram of $L$. monocytogenes isolates. Characterization of $L$. monocytogenes isolates by PCR assay.

\section{Materials and methods}

Samples. A total of 375 samples were collected from buffaloes, bedding and silage as the following: 300 samples were collected from apparently healthy animals (vaginal swabs, nasal swabs, and swabs from eye), bedding and silage samples; 60 sample for each. 75 samples were collected from aborted buffaloes (vaginal swabs, nasal swabs, swabs from eye), bedding and silage, 15 samples for each. The samples were collected from different localities in clean sterile containers. All samples were sent to laboratory in an ice box with a minimum of delay.

Isolation and identification of isolates. It was done according to Quinn et al., (2002).

Media used for identification of Listeria. Listeria Oxford agar supplemented with CCFA., Palcam agar supplemented with Listeria Palcam antimicrobic (SR 150 E) and Trypticase soy medium with $0.6 \%$ yeast extract were used for cultivation, identification, detection of motility as well as for antibiogram assay. Blood agar was used for detection of hemolytic activity of isolates and in CAMP test.

Motility test. it was done according to Federal Register, (1988)

CAMP test. It was done according to Federal Register (1988). For detection of the synergistic reactions of hemolysim of $L$. monocytogenes with beta-toxin of S. aureus.

Pathogenicity in mice. It was done according to Federal Register, (1988). Three mice were used for each isolate. Each mouse was injected intraperitoneally $(\mathrm{I} / \mathrm{P})$ with $0.1 \mathrm{ml}$ of the bacterial 
suspension. Each mouse received approximately $10^{9}$ bacterial cells; three mice were inoculated $\mathrm{I} / \mathrm{P}$ with sterile saline solution and were kept as control. The death rate and post-mortem changes as well as the re-isolation of the organism from the internal organs and heart blood were recorded.

Serotyping of $\boldsymbol{L}$. monocytogenes isolates. It was done according to Federal Register, (1988). Listeria monocytogenes antisera type 1, 4 and $1 / 2$ a (Behring werke AG) were used.

Antibiogram of the isolated strains. The antibiotic sensitivity test was done according to Finegold and Martin, (1982), and the following discs were used: amoxycillin, ampicillin, cephalexin, chloramphenicol, erythromycin, lincomycin, ofloxacin, penicillin G, rifampicin, streptomycin, tetracycline and ceftiofur sodium.

PCR assay. for detection of actA gene in the extracted DNA of $3 \mathrm{~L}$. monocytogenes type 4 isolates according to Xiaohui and Jiao, (2005).

\section{Results and discussion}

All isolates were motile at room temperature, CAMP positive and $\beta$-hemolytic. Serotyping of $11(100 \%)$ L. monocytogenes isolates which were recovered from examined samples, revealed that $6(54.5 \%)$ isolates were serotype 4 and $5(45.5 \%)$ isolates were untyped. The postmortem examination of dead mice revealed the presence of multiple tiny foci of necrosis among spleen and liver as well as congestion of the subcutaneous tissues. Also, L. monocytogenes isolates could be recovered from internal organs and heart blood of dead mice.

Listeriosis is a serious infectious disease caused by Listeria monocytogenes which has been recognized as a significant pathogen, occurring worldwide, capable of causing animal and human infections leading to severe economic losses (Maja et al., 2003).

Table (1) showed the prevalence of $L$. monocytogenes in samples collected from aborted buffaloes as the following. 4(26.7\%), $3(20 \%), 1(6.7 \%), 2(13.3 \%)$, and $1(6.7 \%)$ were positive and 11(73.3\%), $12(80 \%), 14(93.3 \%)$, $13(86.7 \%)$ and $14(93.3 \%)$ were negative samples for L. monocytogenes from vaginal swabs, nasal swabs, swabs from eye, bedding and silage respectively.

Capita et al., (2001) concluded that the Palcam medium was more selective than the modified Oxford medium for isolating Listeria species. Moreover, EL-Gedawy, (2009) indicated that the highest incidence of $L$. monocytogenes was recovered from silage $10 \%$.
But, he could not recover L. monocytogenes from bedding samples.

All isolates were motile at room temperature these results come in agreement with that of Hindy, (2006). All isolates were positive for CAMP test. Also, Mckellar, (1994) stated that CAMP test is used for distinguishing $L$. monocytogenes from other non pathogenic Listeria. In this investigation L. monocytogenes isolates formed narrow zone of $\beta$-hemolysis. Isome et al., (1995) stated that hemolysin (Listeriolysin 0) has been considered as a main component of virulence of $L$. monocytogenes.

Serotyping of L. monocytogenes isolates recovered from examined samples revealed that $6(54.5 \%)$ isolates were typed as serotype 4 . Meanwhile, 5(45.5\%) could not be typed by the available antisera. The obtained results coincided to large extent with that of Hindy, (2006) who typed $14 \mathrm{~L}$. monocytogenes isolates and found that, 4 isolates were belonged to serotype 1 and 8 isolates were typed as serotype 4 , while 3 isolates were untyped.

Antibiogram of 13 chemotherapeutic agents on 11 isolates were presented in Table (2) all isolates were completely resistant to lincomycin and streptomycin. All isolates were 100\% sensitive to ampicillin, chloramphenicol, erythromycin, tetracycline and ceftiofur sodium. While, there wee differences in isolates sensitivity to the other chemotherapeutic agents. In this concern, Hindy, (2006) found that $100 \%$ of the examined isolates were sensitive to ampicillin, $86.7 \%$ to erythromycin, $80 \%$ to chloramphenicol and $73.3 \%$ to amoxycillin, while, $100 \%$ of the examined isolates were resistant to lincomycin and streptomycin.

The data presented in Table (3) indicated that the intraperitoneal injection $(\mathrm{I} / \mathrm{P})$ of mice with $10^{9}$ c.f.u. L. monocytogenes caused $100 \%$ death with in 1-5 days. These results come in agreement with the findings of El-Gedawy, (2009). These results come in accordance with the findings of Parker and Collier, (1990). Results achieved in Table (4), Fig. (1) revealed positive amplification of $827 \mathrm{bp}$ fragment of actA gene was observed from the extracted DNA of $3(100 \%)$ L. monocytogenes isolates. In this concern, Wiedmann et al., (1997) indicated that actA gene providing us with a good opportunity to find new clonal group and to investigate the contamination pattern of $L$. monocytogenes in the environment. Also showing that act $\mathrm{A}$ is a highly polymorphic virulence protein. 
Table (1): Prevalence of Listeria monocytogenes in buffaloes.

\begin{tabular}{|c|c|c|c|c|c|c|c|c|c|c|}
\hline \multirow[t]{3}{*}{ Type of samples } & \multicolumn{10}{|c|}{ Animal status } \\
\hline & \multicolumn{5}{|c|}{ Apparently healthy buffaloes } & \multicolumn{5}{|c|}{ Aborted buffaloes } \\
\hline & No. & $+\mathrm{Ve}$ & $\%$ & $-\mathrm{Ve}$ & $\%$ & No. & $+\mathrm{Ve}$ & $\%$ & $-\mathrm{Ve}$ & $\%$ \\
\hline Vaginal swabs & 60 & 0 & 0 & 60 & 100 & 15 & 4 & 26.7 & 11 & 73.3 \\
\hline Nasal swabs & 60 & 0 & 0 & 60 & 100 & 15 & 3 & 20 & 12 & 80 \\
\hline Swabs from eye & 60 & 0 & 0 & 60 & 100 & 15 & 1 & 6.7 & 14 & 93.3 \\
\hline Bedding & 60 & 0 & 0 & 60 & 100 & 15 & 2 & 13.3 & 13 & 86.7 \\
\hline Silage & 60 & 0.0 & 0.0 & 60 & 100 & 15 & 1 & 6.7 & 14 & 93.3 \\
\hline Total & 300 & 0.0 & 0.0 & 300 & 100 & 75 & 11 & 14.7 & 64 & 85.3 \\
\hline
\end{tabular}

* The percent was calculated according to the number of examined samples.

Table (2): Antibiogram of the isolated strains.

\begin{tabular}{lcccc}
\hline Antibiotic disc used (mg/disc) & \multicolumn{2}{c}{ Sensitive } & \multicolumn{2}{c}{ Resistant } \\
\cline { 2 - 5 } & No. & \% & No. & \% \\
\hline Amoxycillin & 8 & 72.7 & 3 & 27.3 \\
Ampicillin & 11 & 100 & 0.0 & 0.0 \\
Cephalexin & 7 & 63.6 & 4 & 36.4 \\
Chloramphenicol & 11 & 100 & 0.0 & 0.0 \\
Erythromycin & 11 & 100 & 0.0 & 0.0 \\
Gentamycin & 9 & 81.8 & 2 & 18.2 \\
Lincomycin & 0.0 & 0.0 & 11 & 100 \\
Ofloxacin & 8 & 72.7 & 3 & 27.3 \\
Penicillin G & 10 & 90.9 & 1 & 9.1 \\
Rifampicin & 7 & 63.6 & 4 & 36.4 \\
Streptomycin & 0.0 & 0.0 & 11 & 100 \\
Tetracycline & 11 & 100 & 0.0 & 0.0 \\
Ceftiofur sodium & 11 & 100 & 0.0 & 0.0 \\
\hline
\end{tabular}

* The percent was calculated according to the total number of isolates (11).

Table (3): Mice pathogenicity test of L. monocytogenes.

\begin{tabular}{lcccc}
\hline No. of examined isolates & No. of inoculated mice & \multicolumn{2}{c}{ No. of dead mice } & \multirow{2}{*}{ Death within } \\
\cline { 3 - 4 } & & No. & $\%$ & \\
\hline 11 & $33(3$ per isolate $)$ & 33 & 100 & $1-5$ days \\
- Ve control & 3 & 0 & 0 & No deaths \\
\hline
\end{tabular}

* The percent was calculated according to the number of inoculated mice.

Conclusion. It is an important to mention that this investigation aimed to characterize $L$. monocytogenes isolates from Egyptian buffaloes which may contaminate carcasses during slaughter and processing, thereby transmit infection to man and cause human disease. Poorquality silage should not be fed to pregnant animals. Also, feeding methods which minimize direct ocular contact with silage should be implemented. Also, we recommended early and rapid treatment of diseased animals with drug of choice. Moreover, good management should be follow and separation of diseased animals to avoid spread of infection.

\section{References}

Bunning, V.K.; Donnelly, C.W.; Peeler, J.T.; Briggs, E.H.; Bradshaw, J.G.; Crawford, R.G.; Beliveau, C.M. and Tierney, J.T. (1988): "Thermal inactivation of Listeria monocytogenes within bovine macrophages". Appl. Environ. Microbiol., 54, 364-370.

Capita, R.; Alonso, C.C.; Prieto, M.; Garcia, F.M.D.C. and Moreno, B. (2001): "Comparison of PALCAM and modified oxford plating media for isolation of Listeria species in poultry meat following UVMII or Fraser secondary enrichment broth". Food Microbiol., 18(5): 555563.

El-Gedawy, A.A. (2009): "Bacteriological studies on Listeria microorganism in sheep". Ph. D. thesis Vet. Science, Zagazig Univ., Egypt/

Finegold, S.M. and Martin, W.T. (1982): "Diagnostic Microbiology". $6^{\text {th }}$ Ed. C.V. Mosby Co. St. Louis Toronto

Federal Register (1988): "Bacteriological analytical manual chapter 29, Listeria isolation, revised method of analysis". Fed. Regist., 55: 44153-44158.

, London.

Gitter, M.; Richardson, C. and Boughton, E. (1986): "Experimental infection of pregnant ewes with Listeria monocytogenes. Vet. Rec., 118: 575-578. 
Table (4): Characterization of L. monocytogenes isolates by PCR assay

\begin{tabular}{lc}
\hline Examined isolates & ActA gene \\
\hline Isolate No.1 & + \\
Isolate No.2 & + \\
Isolate No.3 & + \\
\hline
\end{tabular}

+: gene present

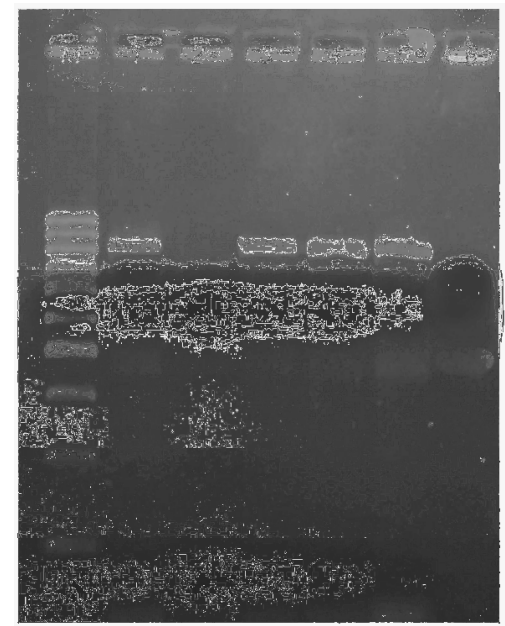

Fig. (1): Shows agarose electrophoresis of PCR amplification of $827 \mathrm{bp}$ Fragments of actA gene from extracted DNA of L. monocytgenes type 4 isolates. Lane $M$ shows 100 bp ladder marker. $(1=+\mathrm{Ve}$ control, $2=-$ Ve control. 3, 4 and 5=examined isolates).

Hindy, B.A.S. (2006): "Further studies on Listeria organisms". Ph. D. thesis (Food Hygiene), Fac. Vet. Med., Cairo Univ., Egypt

Isome, L.L.; Ahmed, A.H. and Martin, S.E. (1995): "Influence of plasmids on catalase and superoxide dismutase activities in L. monocytogenes", J. Food Prot., 58(9): 955-959.

Maja, A.; Dirk, S. and Darinka, V. (2003): "Murine model of pregnancy-associated Listeria monocytogenes infection". Immunol. Med. Microbiol., 35: 177-182.

Mckellar, R.C. (1994): "Use of the CAMP test for identification of L. monocytogenes". Appl. Enviro. Microbiol., 60: 4219-4225.

Parker, M.T. and Collier, L.H. (1990): "Topley and Wilson's principles of bacteriology, virology and immunity". Vol. 28 ${ }^{\text {th }}$, Edward Arnold, a division of Hodder and Stoughton, London. Melbourine Auckland.

Quinn, P.J.; Markey, B.K.; Carter, M.E., Donnelly, W.J.C.; Leonard, F.C. and Maguire, D. (2002): "Veterinary Microbiology and Microbial disease". $1^{\text {st }}$ published, Blackwell Science 1Ed.

Wiedmann, M., Bruce, J.L., Keating, C. Johnson, A.E., McDonough, P.L., and Batt, C.A. (1997): "Ribotypes and virulence gene poly-morphisme suggest three distinct $L$. monocytogenes lineages with differences in pathogenic potential". Infecti. Immunit., 65 (7): 2707-2716.

Xiaohui Zhou and Xinan Jiao (2005): "Molecular grouping and pathogenic analysis of Listeria monocytogenes of clinical and food origin". Food control 16: 867-872.

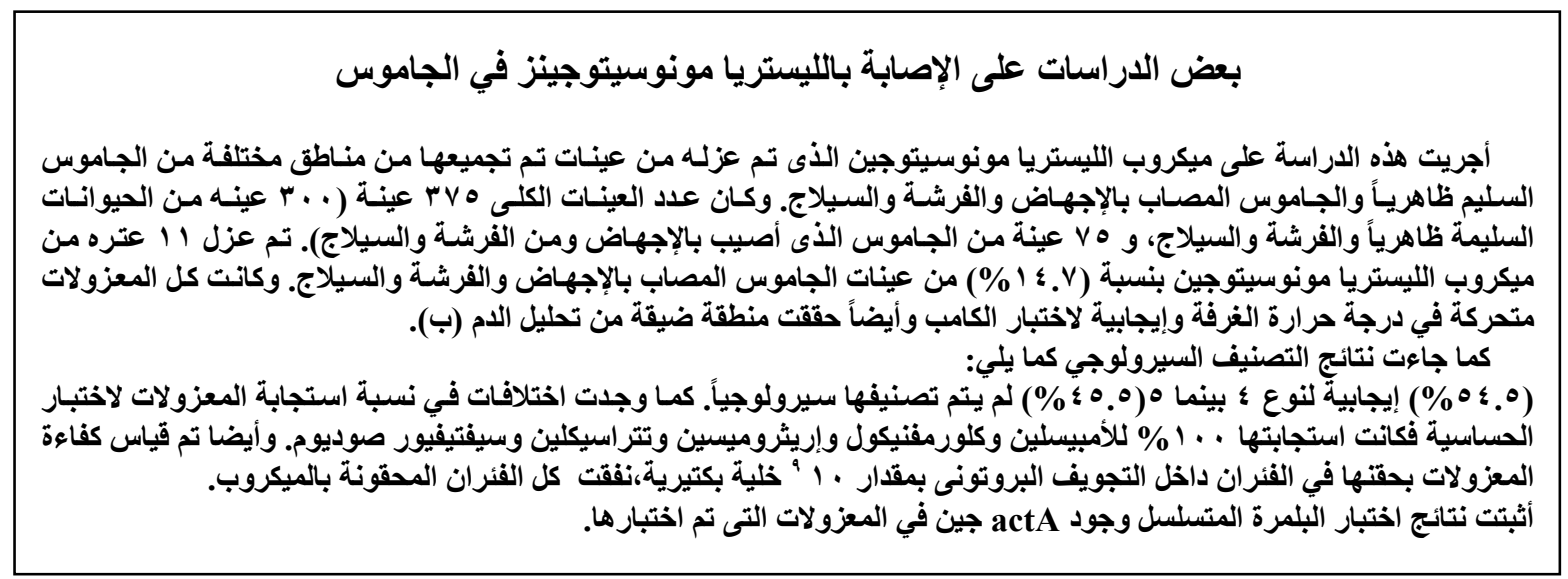

